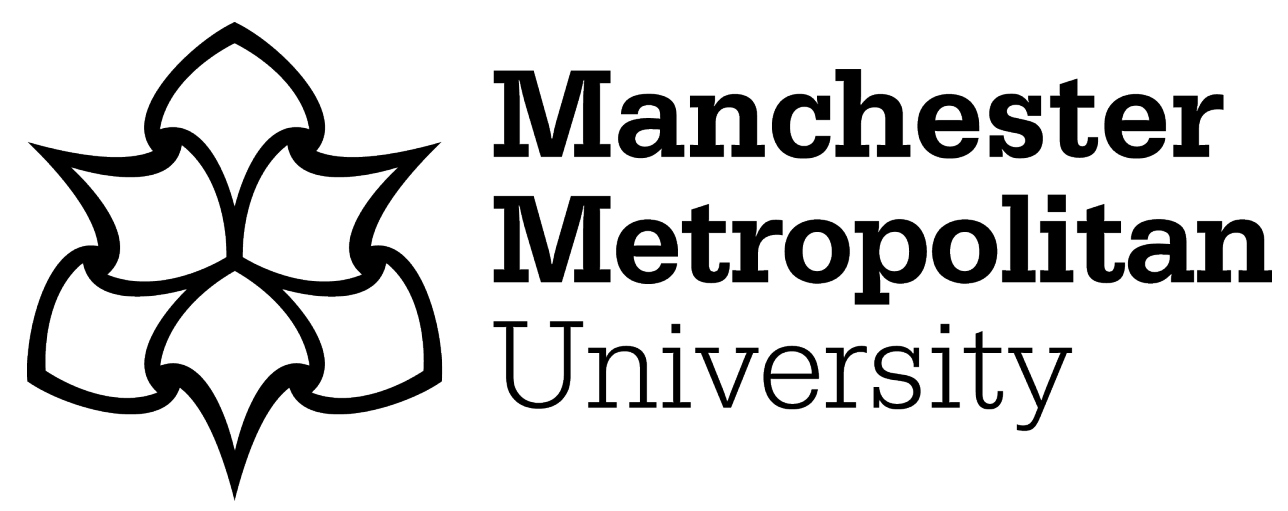

Avila, E, Tagg, N, Willie, J, Mbohli, D, Farfan, MA, Vargas, JM, Bonat, WH, Dupain, J, Epanda, MA, Luyten, I, Tedonzong, L, Peeters, M and Fa, JE (2019) Interpreting long-term trends in bushmeat harvest in southeast Cameroon. Acta Oecologica, 94. pp. 57-65. ISSN 1146-609X

Downloaded from: https://e-space.mmu.ac.uk/619130/

Version: Accepted Version

Publisher: Elsevier

DOI: https://doi.org/10.1016/j.actao.2017.09.007

Usage rights: Creative Commons: Attribution-Noncommercial-No Derivative Works 4.0

Please cite the published version 
3

4

5

6

7

8

9

10

11

12

13

14

15

16

17

18

19

20

21

22

23

24

25

26

27

28

29

30

31

32

\section{Interpreting long-term trends in bushmeat harvest in southeast}

\section{Cameroon}

Eva Ávila a, Nikki Tagg b , Jacob Willie b,c, Donald Mbohli b, Miguel Ángel Farfán d,e , J.

Mario Vargas ${ }^{\mathrm{d}}$, Wagner H. Bonat ${ }^{\mathrm{f}}$, Jef Dupain ${ }^{\mathrm{g}}$, Manfred A. Epanda ${ }^{\mathrm{g}, \mathrm{h}}$, Inge Luyten

b,i, Luc Tedonzong ${ }^{\text {b,c }}$, Martine Peeters ${ }^{j}$, and John E. Fa ${ }^{k, 1, *}$

a Departamento de Biología Animal, Unidad de Vertebrados. Universidad de Barcelona, Barcelona, Spain

${ }^{\mathrm{b}}$ Association de la Protection de Grands Singes (APGS), Cameroon, Centre for

4 Research and Conservation (CRC), Royal Zoological Society of Antwerp (RZSA),

25 Antwerp, Belgium

$26{ }^{\mathrm{c}}$ Terrestrial Ecology Unit, Ghent University, Ghent, Belgium

27 d Departamento de Biología Animal, Universidad de Málaga, Málaga, Spain

28 e Biogea Consultores, Málaga, Spain

$9{ }^{\mathrm{f}}$ Department of Statistics, Paraná Federal University, Curitiba, Paraná, Brazil

30 African Wildlife Foundation, Ngong Road, Karen, Nairobi, Kenya

$31{ }^{\mathrm{h}}$ African Wildlife Foundation, Yaoundé, Cameroon

$32{ }^{\text {i }}$ Faculty of Science, Utrecht University, Utrecht, The Netherlands 
33 j UMI 233, Institut de Recherche pour le Développement (IRD) and Université de

34 Montpellier 1, Montpellier, France

$35{ }^{\mathrm{k}}$ School of Science and the Environment, Manchester Metropolitan University,

36 Manchester, UK

$37{ }^{1}$ Center for International Forestry Research, CIFOR Headquarters, Bogor, Indonesia

38

$39 *$ Corresponding author. School of Science and the Environment, Manchester

40 Metropolitan University, John Dalton Building, Manchester M15 6BH.

41 E-mail address: jfa949@gmail.com (J.E.Fa)

42

43 
- Long-term monitoring of hunting offtake in tropical forests is fundamental to achieve sustainability.

- Catch per hunter per day and mean body mass indicator of hunted prey can be used to document extraction patterns over time.

49

- Notwithstanding some caveats, these measures can still be used as a good indication of changes in prey offtake.

51

52 


\section{Abstract}

54 Measuring hunting sustainability across West/Central African forests remains a challenge. Long-term assessment of trends is crucial. Via hunter-reported surveys we collected offtake data in three villages near the Dja Biosphere Reserve (southeast

57 Cameroon). During four months (March-June) in 2003, 2009 and 2016, we gathered

58 information on hunters, prey species and number of carcasses brought to the three settlements. Because it was not possible to record hunter effort i.e. the time a hunter spent pursuing animals or setting traps, to calculate catch per unit effort (CPUE), we used catch per hunter per day (CPHD) to document hunter returns. We then used the changes in the mean body mass indicator (MBMI) throughout the study period to test for defaunation in the three villages. Differences in CPHD and MBMI by month and year, between villages and hunting method, were investigated using Tweedie regression models. For all species pooled, we found that the mean CPHD remained relatively constant between 2003 and 2016. There was an observed shift from traps to firearms during the study period. CPHD for each of the seven most hunted species did not vary significantly during the entire study period, and a similar change from traps to firearms was observed. MBMI also remained stable for all species pooled, but significantly declined in the remotest village. Starting MBMI values for this village were higher than for the other two settlements perhaps because wildlife here is less depleted. Although hunter effort data may be difficult to obtain over long time periods, CPHD and MBMI may be useful tools as a measure of impact of hunters on prey populations.

74 Keywords: bushmeat, hunter offtake, mean body mass indicator, mammals, tropical

75 rainforests

\section{Introduction}


It is now widely recognized that hunting above sustainable levels is one of the main causes of worldwide biodiversity loss (Robinson \& Bennett 2000; Milner-Gulland et al. 2002). In tropical forest regions, where standing biomass of wildlife is significantly lower than in more open habitats, overhunting of wild animals for their flesh (bushmeat) may lead to the depletion of local populations and even contribute to the extinction of some species (Abernethy et al. 2013).

Uncontrolled bushmeat hunting in African rainforests results in large-bodied species, species with slower life histories, often frugivores, and those with high hunter or black market value to disappear first. As a result, more smaller-bodied taxa are then targeted; the latter (large rodents and small duikers) possess higher reproductive potentials that confer them greater resilience to heavy hunting pressure. Although evidence for the universality of such pattern of defaunation is still debated, given confounding effects such as hunter choice (see Luiselli et al. 2017), some studies have shown that potentially overexploited hunting catchment areas are characterized by a preponderance of smaller-bodied game species (Fa et al. 2015). This phenomenon has been measured by the 'mean body mass indicator' (MBMI) in different sites and time scales where the MBMI drops as the proportion of small-bodied species in the offtake increases (Ingram et al. 2015). This index can arguably be employed (assuming a linear relation between percent of small prey and large species loss) as a proxy of defaunation (Dirzo et al. 2014) in a habitat. The MBMI can be seen as analogous to the 'large fish index' (LFI), which reveals changes over time in the contribution of large-bodied fish to the biomass of the catch (Greenstreet et al. 2011; Shephard et al. 2011).

Sustainability of hunted game populations is often impractical to assess directly given that the estimation of game populations in the field requires considerable investment of time and money. Consequently, indices such as 'catch per unit effort' 
102 (CPUE) are useful for comparative studies, i.e. to indicate that hunting pressure is

103

104

105

106

107 higher in a site in contrast to another (Puertas \& Bodmer 2004; Rist et al. 2010; GrandeVega et al. 2015). Furthermore, data reported by hunters themselves, can be used to investigate exploitation levels, gain insights into the status of a harvested population, and approximate sustainability of hunting. Despite some potential biases due to misreporting or unwilling hunter participation, self-reporting hunter data provide useful information and is often the most cost-effective option for assessing hunting impacts (Rist et al. 2010). However, a major limitation in measuring hunting impact is linked to the difficulty of recording the time dedicated to hunting, since gathering such information requires intensive monitoring of hunters via hunter follows (e.g. Kümpel et al. 2008) or the reporting by hunters of the time spent engaged in the pursuit of prey (e.g. Grande-Vega et al. 2015). However, the number of hunted animals brought to a camp or village can often be counted more easily, and in some cases quarry can be ascribed to specific hunters. This type of data, although a measure of hunter returns only, can with some caution still be used to assess whether the catch per hunter over a set period is diminishing, stable or increasing. Like CPUE and MBMI indices, hunter returns are proxies of hunting impact.

Over a 13-year period, we recorded the species and number of individual animals killed by known hunters in three villages in southeastern Cameroon. Using these data, we described changes in hunter returns (catch per hunter per day, CPHD) for all species pooled and for the more frequently hunted species. Since hunter effort was not logged, because of the inherent difficulties in accurately obtaining this information, offtake per hunting trip could not be calculated as a proxy for changes in prey abundance. However, we estimated the average number of animals a hunter brought back to the village in a day over the entire study period. To determine if there was 
evidence of faunal depletion within the three study villages, we used the MBMI for all animals hunted to assess whether hunters relied increasingly on smaller species over time. We test whether there were spatial and temporal differences in the CPHD and MBMI between villages, and hunting methods. Finally, we argue that the offtake data gathered in our study, despite potential shortcomings, can be used as an indirect measure of offtake in the study area.

\section{Methods}

\subsection{Study area}

The three study villages, Malen V (MV), Duomo-Pierre (DP) and Mimpala (MIM), are situated at the northeastern periphery of the Dja Biosphere Reserve (DBR) in southeastern Cameroon (Fig. 1); the DBR encompasses a total area of 5,260 $\mathrm{km}^{2}$ and is noted for its rich biodiversity (Betti 2004). The main type of habitat in the region is near-primary forest and secondary forest, ranging from areas with closed canopy and little undergrowth to zones with a relatively open canopy and dense undergrowth (Dupain et al. 2004; Tagg et al. 2015; Tagg \& Willie 2013). Swampy areas are also found near the River Dja. Rainfall is around $1500 \mathrm{~mm} / \mathrm{year}$, divided into two rainy seasons and two dry seasons (Willie et al. 2012). Mean temperatures are fairly constant, around $24^{\circ} \mathrm{C}$ (McSweeney et al. 2010).

MV is the largest of the three villages (Table 1) and the most accessible by motorized vehicles; the closest markets are at Messamena (60km away), and Abong Mbang (100km away). MV is comprised of three smaller settlements (MV, Diassa and Palestine), which we treat here as one (Luyten 2009). Total population size for the three villages was around 300 inhabitants and settlement sizes did not vary substantially during the study period (Table 1). 

pygmies also reside there. Villagers are generally poor, with an average income of less than $\$ 1$ per capita per day. These communities are amongst the least developed (i.e., infrastructure such as roads, schools and health centers is lacking in most villages) and least educated in the country (Tagg et al. 2011; Tagg \& Willie 2013). Most people fish, hunt, harvest or gather forest products and many are engaged in some form of subsistence agriculture. Bushmeat is hunted mainly for subsistence; only a small proportion is sold (Epanda et al. 2005).

Protection de Grands Singes (APGS) of the Zoological Society of Antwerp (Tagg et al. 2011) since 2001. Through awareness raising, education and creation of alternative income, APGS has tried to discourage the use of firearms and hunting of protected species such as elephant and great apes (A or B categories of the Cameroonian Wildlife Law) within clearly delimited community hunting areas (Fig. 1). The law also prohibits respected, including sanctioning of perpetrators if caught (Epanda et al. 2005).

\subsection{Bushmeat surveys}

173 In each study village, we gathered data during three distinct study periods: August 2002-August 2003, March-June 2009 and February-September 2016. We employed a research assistant in each village (thus familiar with the community, the area and the dialect) to build trust, avoid biases, and maximize reliability of the data collected. To 
177 allow for inter-annual comparisons we only used data gathered during March-June,

178 since records for these four months were available for all study years. This period

179 encompassed the end of the long dry season, the entire short rainy season (from mid-

180 March to mid-June), and the start of the short dry season.

181 We employed data collectors in each village to document all bushmeat brought

182 to their village at the end of each study day. Hunters willingly brought their catch to the

183 data collectors when returning from a hunting trip. For each carcass, the data collectors

184 recorded the identity of the hunter, species, hunting method used (trap, firearm, dog, net

185 or collected by hand), and in some cases the condition of the carcass (dried, smoked,

186 fresh or alive) and its weight. We were not able to document the time spent by a hunter

187 either setting traps or pursuing animals to shoot.

\subsection{Measuring offtake}

Hunter returns

191 We calculated average monthly hunter returns by dividing the total number of carcasses

192 recorded for each hunter by the total number of days in which a hunter reported prey

193 items in a month: per month. 
201 We employed the mean body mass indicator (MBMI) to investigate temporal changes in

202

203

204

205

206

207

208

209

210

211

212

213

214

215

216

217

218

219 the composition of hunted species (Ingram et al. 2015). We estimated MBMI only for mammal species since this group represented the majority of animals hunted (Appendix S1). We used the species' mean body weight (adult males and females pooled) available from the literature (Kingdon et al. 2013). We calculated the MBMI as follows:

$$
\mathrm{MBMI}=\frac{\sum(M B W i * n i)}{N}
$$

where $M B W i$ is a species' body weight, $n_{i}$ is the number of carcasses recorded for that species, and $N$ is the total number of carcasses of all species. MBMI was estimated for each hunter each month, for each village, and for each hunting method.

\section{Statistical Analyses}

We assessed temporal changes in CPHD and MBMI over the three study periods. We also tested the effect of the covariates: village (MV, DP and MIM), study year (2003, 2009 and 2016), month (March, April, May and June) and hunting method (firearms and traps). We used eight CPHD response variables corresponding to the sum of all species and for those species that had more than 100 carcasses. We also fitted an additional model for the response variable MBMI.

We fitted nine independent Tweedie regression models (Bonat \& Kokonendji 2016) using hunter data (1027 observations). In all models, the linear predictor was composed of the effect of the four main covariates with interaction effects up to a second order. We adopted the orthodox logarithm link function. We fitted the models using the maximum likelihood method. We used the statistical software R (R Core Team 2015). Since our nine response variables are continuous, but with a probability 
mass at zero (Appendix S2), Tweedie regression models are suitable to deal with these types of data (Shono 2008; Arcuti et al. 2013).

We were also interested in certain comparisons, such as differences between villages in terms of hunting method, or over time. For this, we employed procedures for multiple comparisons. The R package doBy (Højsgaard \& Halekoh 2016) was used to compute differences between villages, years, hunting methods, as well as possible interactions between these effects. For such multiple comparisons tests, Bonferroni corrections are recommended for the associated $p$-values. In this paper, we employed the multcomp package (Hothorn et al. 2008) to compute such corrections.

For each response variable we fitted a saturated model, i.e. a model with all main and interaction effects, and subsequently performed a Wald-ANOVA type test to remove all non-significant effects. We use 95\% confidence levels. We then fitted a second model with the linear predictor composed only from the significant effects of the previous model and interpreted the results using multiple comparison techniques. By removing the non-significant terms, we simplified the presentation of our results, thus making them easier to interpret. Furthermore, we gained more power to test the remained effects.

\section{Results}

\subsection{General patterns}

A total of 27 mammals, one bird and three reptile species were hunted during the study (Appendix S1). More than 50\% of carcasses recorded in all villages were ungulates, followed by rodents (20-28\%) and then primates (8-11\%). Pangolins (one species) amounted to $5-7 \%$ of all carcasses, small carnivores around $5 \%$, while birds and reptiles 
less than $2 \%$. The number of hunted species for the three villages ranged between 26 in 2016 and 31 in 2003.

For the three villages pooled, the total numbers of recorded animals hunted and number of reporting hunters varied between years (Table 1). Only $17(8 \%)$ of the total 214 recorded hunters in the three villages remained active during all year-periods. Out of the total of number of carcasses for the three villages (Table 1), almost half (48\%) were hunted in MV, $26 \%$ in DP, and 26\% in MIM.

Animals were trapped (both foot and neck traps) and killed by firearms (shotguns), nets, dogs, or by hand. A total of 1471 animals (56\%) were trapped and 1003 shot (38\%) (Table 1); the rest (6\%) were taken with other methods. Around half of all ungulates were trapped, the other half shot. However, more than $80 \%$ of primates were shot and almost $80 \%$ of rodents were trapped. The most commonly hunted species (>100 carcasses), all mammals, were: brush-tailed porcupine (Atherurus africanus), Peter's duiker (Cephalophus callipygus), Bay duiker (Cephalophus dorsalis), mustached guenon (Cercopithecus cephus), giant pouched rat (Cricetomys emini), longtailed pangolin (Phataginus tetradactyla) and blue duiker (Philantomba monticola). Of these, the blue duiker was the most frequently hunted species in all study years and villages (see data in Appendix S3).

\subsection{Changes in $C P H D$}

Mean monthly CPHD for the entire study period was $1.55 \pm 0.08$ (range 1-2.86). CPHD for the three villages over the study period did not drop significantly (Fig. 2). Year and Method, but not Month, were significant predictors of CPHD (Fig. 3). However, there were significant interactions for Village/Year, Village/Method, and Method/Month (Table 2). 

factor of $6.52, p$-value $<0.00)$, but decreased by 2.77 ( $p$-value $<0.00)$ for traps during the same period (Fig. 3, Appendix S4, Table S1). Firearm use differed between villages MV and DP, and MV and MIM (Appendix S4, Table S2) but no difference appeared between villages in trap use. CPHD for firearms was on average 1.57 times ( $p$-value $=$ 0.02) greater in March than in June, but 1.97 times lower in March than in June for traps $(p$-value $<0.00)$ (Appendix S4, Table S3). The interaction Village/Year was significant for five species (C. callipygus, $C$. dorsalis, Cer. cephus, C. emini, P. monticola); Village/Method for two species ( $A$. africanus, Cer. cephus); Method/Month for A. africanus and P. monticola; and Year/Method for six of the seven species considered (the exception being Cer. cephus where no interaction was found). The same four interaction effects were also significant for all species pooled (Table 2). the three most hunted ungulates: P. monticola, C. dorsalis and C. callipygus. For all ungulate species, the CPHD for firearms between 2003 and 2016 increased by a factor of 9.00 ( $p$-value $<0.00$ ) for P. monticola (Appendix S4, Table S15), by 11.19 (p-value $<0.00$ ) for C. callipygus (Appendix S4, Fig. S2 and Table S8), and by 7.99 ( $p$-value < 0.00) for C. dorsalis (Appendix S4, Fig. S3 and Table S9, S10). In contrast, CPHD for traps decreased by $6.45(p$-value $<0.00)$ for P. monticola, $10.42(p$-value $<0.00)$ for $C$. callipygus and by $7.89(p$-value $<0.00)$ and 3.35 ( $p$-value 0.01$)$, between 2003 and 2009, and 2003 and 2016, for C. dorsalis, respectively. Village and Year CPHD differences for P. monticola were higher in MV than MIM and DP, but only in 2009 
differed only for P. monticola where CPHD for traps increased from March to June (Appendix S4, Fig. S7 and Table S16). No species showed any significant interaction between Method/Month.

There were no significant temporal changes according to hunting method observed for C. emini (Appendix S4, Fig. S5). However, in the case of A. africanus, CPHD for firearms increased by a factor of 9.87 ( $p$-value $<0.00$ ) from 2003 to 2016, but CPHD for traps decreased by 2.71 for the same period. For A. africanus, MV differed significantly from DP and MIM in the use of firearms (Appendix S4, Table S4) but trap use increased from March to June in all villages, in all years (Appendix S4, Fig. For P. tetradactyla we found only a significant interaction effect between

\subsection{Changes in MBMI}

Average monthly MBMI was $5.98 \pm 0.25 \mathrm{~kg}$ (range $2.82-9.40)$ and did not vary 
We found no significant interaction effects for Village/Method, Village/Month,

326 Year/Method and Year/Month. Only in 2009 did we find significant differences

327 between DP and MIM, and between MV and MIM (Fig. 5 and Appendix S5, Table S1).

328 On average, MIM had MBMI values $1.83(p$-value $<0.00)$ and $1.50(p$-value $<0.00)$

329 larger than DP and MV, respectively. For 2003 and 2016 we found no evidence of

330 significant differences between villages.

331 For both hunting methods, we detected a significant difference only between the months April and May. The MBMI increased for animals taken with firearms, but decreased for traps. We found no significant differences for all other comparisons (Appendix S5, Tables S2-S3).

\section{Discussion}

A main goal of the APGS program is to instate a self-management system of

wildlife resources that would contribute to the livelihoods of people without endangering animal populations or their ecological functions. Hunters in the three study villages were asked to comply with the memorandum of understanding signed between the villages and APGS (Epanda et al. 2005; Luyten 2009). As part of this agreement, hunters allowed APGS to record daily numbers of animals killed in each village.

Although hunters were active within community hunting zones defined by the APGS agreement, hunting with firearms could not be controlled or trapping regulated (Luyten 2009).

Our results show that the average CPHD and MBMI in the study villages did not drop over time. From a hunter's perspective, the number of animals brought to the villages every day was similar throughout the study period, although substantial variation existed between hunters. However, our metrics may mask the possibility that 
hunting trips may have become longer if prey populations around the villages became more depleted. We have no evidence that hunters were moving out of the mapped community hunting areas. Moreover, hunting effort data gathered for the study villages in 2002, 2005 and 2009 indicate that most trap hunters only undertook day-long trips spending on average 4.60 hours per week hunting (Epanda et al. 2005; Luyten 2009). Day-long trips are usual in subsistence hunting situations, typical in our study villages, since men who hunt for their home consumption are also engaged in other activities such as farming so they do not spend multiple days away from the village. Furthermore, there is no evidence that hunters were venturing further from their villages over time. In fact, the contrary may have been the case since the overall hunting area for the three villages was $111.5 \mathrm{~km}^{2}$ in 2002 and significantly smaller $\left(43.8 \mathrm{~km}^{2}\right)$ in 2009 (Luyten 2009), even though CPHDs remained stable. Moreover, despite an increase in hunters, the lack of variation in CPHD and MBMI throughout the 13-year period may be an indication that the forests around the three study villages possess relatively high animal observation that increasingly larger animals were taken using firearms by the end of the study period. This is confirmed by the rise in the overall MBMI values for animals taken with firearms, but not for those caught in traps. This change in hunter choice of methods could be a response to either hunters having more money to buy weapons, or an increased opportunity to buy cheaper guns. There is evidence that from 2005/2006 shotguns have become more numerous in the three villages (Willie 2006; Tagg et al. 2011) and that bushmeat traders began to supply hunters with cartridges in exchange for hunted animals (Luyten 2009). This penetration of the study villages by middlemen 
375 (who use motorbikes), can explain the higher offtake observed in the road-accessible

376 Malen V and the greater amounts of bushmeat sold, as reported by Luyten (2009).

377 However, a decline in MBMI was only detected in Mimpala, the furthest village from

378 the road. This drop is probably attributable to the fact that starting MBMI values

379 recorded for this village were highest in 2003, explicable by the village's closer

380 proximity to the DBR (see Fig. 1). That larger-bodied animals have become scarcer

381 around this village could be explained by the influx of more shotguns in more recent 382 years.

We are aware that there are limitations to the type of data gathered in this study and that caution should be exercised when interpreting the observation of constancy in hunter returns. However, it is possible that, as suggested by Luyten (2009), the selfmanagement of natural resources and economic development in the three villages has had positive impacts between 2002 and 2004, but has floundered after 2009. The main support for this argument is the apparent increase in the bushmeat trade and the upsurge in firearm use; the latter being strictly forbidden in the APGS hunting management plan. Despite this, wildlife surveys in forest blocks adjacent to the study villages have indicated that wildlife did not drastically vary between 2002, 2006 and 2009 (Luyten 2009) and between recent surveys (Tagg, unpublished data). investment in research is limited. Participatory systems may shorten decision-making time frames promote local autonomy in resource management and strengthen community resource rights (Brook and McLachlan 2008; Danielsen et al. 2009). Participatory, adaptive management of wildlife use requires efficient monitoring systems designed to address impacts at appropriate temporal and spatial scales, while involving both scientific experts and local resource users (Luzar et al. 2011). Ideally, 
metrics that allow conservation managers or communities themselves to understand patterns, track changes, and revise and update regulations affecting hunting, are fundamental. However, collecting data on spatial and temporal changes in hunting offtake to assist a community to regulate their impact on prey numbers can be demanding if hunters are required to provide daily data on hunter effort and number of animals killed. The difficulty of convincing hunters to partake in self-monitoring activities is exemplified by a study of hunters in five communities in the Piagaçu-Purus Sustainable Development Reserve in Brazil in which only 37 out of 74 (50\%) potential monitors, and $36 \%$ of initially interested families, participated (Vieira et al. 2015). If monitoring of hunters is to be assisted by researchers (e.g. Coad et al. 2013) the costs of this would increase dramatically, especially if hunter follows are undertaken. Data on each hunting event such as time dedicated to hunting and location of hunt are more time-consuming to collect for every hunter especially if long-term trends are required to assess. Thus, more cost-effective means of recording and using data on hunter offtake are required for hunting monitoring systems to be maintained over long periods. A practical way forward may comprise describing hunting offtake by gathering data that are simpler to collect, pertaining to animals hunted (number of animals taken by species, sex and relative age of animals) and hunter identity within a village or camp. We argue that CPHD and MBMI can be used alongside more basic hunter interviews at may provide the information required to allow practitioners and communities to sustainably manage their wildlife resources. 
426 Funding was received from Institut de Recherche et Développement (IRD), Montpellier

427 and from the Centre for Research and Conservation (CRC) of the Royal Zoological

428 Society of Antwerp (RZSA), Antwerp, Belgium. H de Nys at IRD and B Banyimbe for

429 their support. APGS technical team in Cameroon for providing in-country logistics.

430

431

Authors' contribution

432 Eva Ávila, analyzed the data and drafted the first version of this article.

433 Nikki Tagg, revised the manuscript.

434 Jacob Willie, revised the manuscript.

435 Donald Mbohli, collected field data.

436 Miguel Ángel Farfán, revised the manuscript.

437 J. Mario Vargas, revised the manuscript.

438 Wagner H. Bonat, led the statistical analyses and revised the manuscript.

439 Jef Dupain, revised the manuscript.

440 Manfred A. Epanda, collected field data.

441 Inge Luyten, revised the manuscript.

442 Luc Tedonzong, collected field data.

443 Martine Peeters, revised the manuscript.

444

445 Supporting Information

446 The list of hunted species (Appendix S1), number of carcasses recorded per species,

447 village, month and year (Appendix S2), raw data (Appendix S3), statistical results for

448 CPUE (Appendix S4) and for MBMI analyses (Appendix S5). The authors are solely 
responsible for the content and functionality of these materials. Queries (other than absence of the material) should be directed to the corresponding author.

\section{References}

Abernethy, K. A., Coad, L., Taylor, G., Lee, M. E. and F. Maisels. 2013. Extent and ecological consequences of hunting in Central African rainforests in the twenty-first century. Philosophical Transactions of the Royal Society B: Biological Sciences 368:20120303.

Arcuti, S., Calculli, C., Pollice, A., D’Onghia, G., Majorano, P. and A. Tursi. 2013. Spatio-temporal modelling of zero-inflated seep-sea shrimp data by Tweedie generalized additive. Statistica 73:87-101.

Betti, J. L. 2004. Impact of forest logging in the Dja Biospehere Reserve, Cameroon. Yaoundé, Ministry of Environment and Forestry/PSRF.

Bonat, W. H. and C. C. Kokonendji. 2016. Flexible Tweedie regression models for continuous data. arXiv:1609.03297v1 [stat.ME] [Accessed 12 September 2016]

Brook R.K. and S.M. McLachlan. 2008. Trends and prospects for local knowledge in ecological and conservation research and monitoring. Biodiversity and Conservation 17:3501-3512

Danielsen, F., Burgess, N.D., Balmford, A., Donald, P.F., Funder, M., Jones, J.P.G., Alviola, P., Balete, D.S., Blomley, T., Brashares, J., Child, B., Enghoff, M., Fjeldså, J., Holt, S., Hübertz, H., Jensen, A.E., Jensen, P.M., Massao, J., Mendoza, M.M., Ngaga, Y., Poulsen, M.K., Rueda, R., Sam, M., Skielboe, T., Stuart-Hill, G., Topp-Jørgensen, E. and D. Yonten. 2009. Local participation in natural resource monitoring: a characterization of approaches. Conservation Biology 23:31-42. 
Dirzo, R., Young, H. S., Galetti, M., Ceballos, G., Isaac, N. J. B. and B. Collen. (2014). Defaunation in the Anthropocene. Science 345:401-406.

Dupain, J., Guislain, P., Nguenang, G. M., De Vleeschouwer, K. and L. Van Elsacker. 2004. High chimpanzee and gorilla densities in a non-protected area on the northern periphery of the Dja Faunal Reserve, Cameroon. Oryx 38:1-8.

Epanda, M.A., Dupain, J., Koffi, K.B. and S.D. Djoufack. 2005. The implementation of a participatory management plan for sustainable hunting within an integrated conservation and development project at the periphery of the Dja Faunal Reserve (Cameroon). Projet Grands Singes, Yaoundé, Cameroon.

Fa, J. E., Olivero, J., Farfán, M. A., Márquez, A. L., Duarte, J., Nackoney, J., Hall, A., Dupain, J., Seymour, S., Johnson, P. J., Macdonald, D. W., Real, R. and J.M. Vargas. 2015. Correlates of bushmeat in markets and depletion of wildlife. Conservation Biology 29:805-815.

Grande-Vega, M., Farfán, M. A., Ondo, A. and J. E. Fa. 2015. Decline in hunter offtake of blue duikers in Bioko Island, Equatorial Guinea. African Journal of Ecology 54:49-58.

Greenstreet, S. P. R., Rogers, S. I., Rice, J. C., Piet, G. J., Guirey, E. J., Fraser, H. M. and R. J. Fryer. 2011. Development of the EcoQO for the North Sea fish community. ICES Journal of Marine Science 68:1-11.

Højsgaard, S. and U. Halekoh. 2016. doBy: Groupwise statistics, LSmeans, linear Contrasts, utilities. R package version 4.5-15. Available: http://CRAN.R project.org/package=doBy [Accessed 14 September 2016]

Hothorn, T., Bretz, F. and P. Westfall. 2008. Simultaneous inference in General Parametric Models. Biometrical Journal 50:346-363.

Ingram, D. J., Coad, L., Collen, B., Kümpel, N. F., Breuer, T., Fa, J. E., Gill, D. J. C., 
Maisels, F., Schleicher, J., Stokes, E. J., Taylor, G. and J. P. W. Scharlemann. 2015. Indicators for wild animal offtake: methods and case study for African mammals and birds. Ecology and Society 20:40. http://dx.doi.org/10.5751/ES$\underline{07823-200340}$

Kingdon, J., Happold, D., Butynski, T., Hoffman, M., Happold, M. and J. Kalina. (eds). 2013. Mammals of Africa (6 vols). Bloomsbury Publishing, London.

Kümpel, N. F., Milner-Gulland, E. J., Rowcliffe, J. M. and G. Cowlishaw. 2008. Impact of gun-hunting on diurnal primates in continental Equatorial Guinea. International Journal of Primatology 29:1065-1082.

Luyten, I. 2009. Evaluating the effectiveness of an integrated conservation and development project. Master thesis. Utrecht University, Netherlands.

Luiselli, L., Petrozzi , F., Akani, G.C., Di Vittorio, M., Amadi, N., Ebere, N., Dendi, D., Amori, G., Eniang, E.A. 2017. Rehashing bushmeat - interview campaigns reveal some controversial issues about the bushmeat trade dynamics in Nigeria. Revue d'Ecologie (Terre et Vie), 72: 3-18.

Luzar, J. B., Silvius, K. M., Overman, H., Giery, S. T., Read, J. M. and J. M. V. Fragoso. 2011. Large-scale environmental monitoring by indigenous peoples. BioScience 61:771-781.

McSweeney, C., New, M. and G. Lizcano. 2010. UNDP Climate Change Country Profile: Cameroon. Available: http://country-profiles.geog.ox.ac.uk/ [Accessed 16 August 2016]

Milner-Gulland, E. J., Bennett, E. L. and the SBS 2002 Annual Meeting Group 2003. Wild meat: the bigger picture. TRENDS in Ecology and Evolution 18:351-357.

Puertas P. E. and R. E. Bodmer. 2004. Hunting effort as a tool for community-based wildlife management in Amazonia. Pages 123-136 in K. M. Silvius, R. E. 
Bodmer and J. M. V. Fragoso, editors. People in nature: wildlife conservation in South and Central America. Columbia University Press, New York, USA.

R Core Team 2015. R: A language and environment for statistical computing. $\mathrm{R}$ Foundation for Statistical Computing, Vienna, Austria. URL https://www.Rproject.org/ [Accessed 14 September 2016]

Rist, J., Milner-Gulland, E. J., Cowlishaw, G., and M. Rowcliffe. 2010. Hunter reporting of Catch Per Unit Effort as a monitoring tool in a bushmeatharvesting system. Conservation Biology 4:489-499.

Robinson, J. G. and E. L. Bennett. 2000. Hunting for sustainability. Columbia University Press, New York.

Shephard, S., Reid, D. G. and S.P.R. Greenstreet. 2011. Interpreting the large fish indicator for the Celtic Sea. ICES Journal of Marine Science 68:1963-1972.

Shono, H. 2008. Application of the Tweedie distribution to zero-catch data in CPUE analysis. Fisheries Research 93:154-162.

Tagg, N. and J. Willie. 2013. The influence of transect use by local people and reuse of transects for repeated surveys on nesting in Western Lowland Gorillas (Gorilla gorilla gorilla) and Central Chimpanzees (Pan troglodytes troglodytes) in Southeast Cameroon. International Journal of Primatology 34:554-570.

Tagg, N., Petre, C.-A. and J. Willie. 2011. Evaluating the effectiveness of a 10-year old Great Ape Conservation Project in Cameroon. Pan Africa News 18:20-23.

Tagg, N., Willie, J., Duarte, J., Petre, C.-A. and J.E. Fa. 2015. Conservation research presence protects: a case study of great ape abundance in the Dja region, Cameroon. Animal Conservation 18:489-498.

Vieira, M. von Muhlen, E. M. and G. H. Shepard Jr. 2015. Participatory monitoring and management of subsistence hunting in the Piagaçu-Purus Reserve, Brazil. 
550 Willie, J. 2006. Contribution a l'evaluation de l'incidence de la chasse sur les populations de cephalophes de la peripherie nord de la reserve de biosphere du Dja (Est-Cameroun). Master's thesis. University of Dschang, Cameroon.

553 Willie, J., Petre, C.-A., Tagg, N. and L. Lens. 2012. Evaluation of species richness estimators based on quantitative performance measures and sensitivity to patchiness and sample grain size. Acta Oecologica 45:31-41.

556 
Table 1 - Summary of offtake results per village and year.

\begin{tabular}{|c|c|c|c|c|c|c|c|c|c|c|c|c|}
\hline \multirow{3}{*}{ Variables } & \multicolumn{12}{|c|}{ Village/Year } \\
\hline & \multicolumn{3}{|c|}{ Duomo Pierre } & \multicolumn{3}{|c|}{ Malen V } & \multicolumn{3}{|c|}{ Mimpala } & \multicolumn{3}{|l|}{ Total } \\
\hline & 2003 & 2009 & 2016 & 2003 & 2009 & 2016 & 2003 & 2009 & 2016 & 2003 & 2009 & 2016 \\
\hline Total village population size ${ }^{1}$ & 82 & 71 & 85 & 143 & 163 & 152 & 98 & 81 & 71 & 323 & 315 & 308 \\
\hline Total number of hunters & 12 & 18 & 29 & 23 & 38 & 36 & 18 & 27 & 18 & 53 & 79 & 82 \\
\hline Total number of recorded carcasses & 412 & 105 & 174 & 377 & 598 & 283 & 247 & 259 & 170 & 1036 & 962 & 627 \\
\hline Numbers hunted/traps & 376 & 34 & 61 & 359 & 179 & 75 & 203 & 128 & 56 & 938 & 341 & 192 \\
\hline Numbers hunted animals with firearms & 19 & 62 & 77 & 10 & 405 & 195 & 29 & 98 & 108 & 58 & 565 & 380 \\
\hline Total number of hunted species & 19 & 22 & 19 & 22 & 23 & 22 & 27 & 25 & 20 & 31 & 30 & 26 \\
\hline
\end{tabular}

${ }^{1}$ Demographic data for each village obtained for 2002, 2009 and 2015 (unpublished data). 


\begin{tabular}{|c|c|c|c|c|c|c|c|c|c|}
\hline \multirow[b]{2}{*}{ Effects } & \multirow[b]{2}{*}{ df } & \multicolumn{8}{|c|}{$\mathrm{W}$ ( $p$-value) } \\
\hline & & All species & $\begin{array}{l}\text { Atherurus } \\
\text { africanus }\end{array}$ & $\begin{array}{l}\text { Cephalophus } \\
\text { callipygus }\end{array}$ & $\begin{array}{l}\text { Cephalophus } \\
\text { dorsalis }\end{array}$ & $\begin{array}{l}\text { Cercopithecus } \\
\text { cephus }\end{array}$ & $\begin{array}{l}\text { Cricetomys } \\
\text { emini }\end{array}$ & $\begin{array}{l}\text { Phataginus } \\
\text { tetradactyla }\end{array}$ & $\begin{array}{l}\text { Philantomba } \\
\text { monticola }\end{array}$ \\
\hline Village & 2 & $2.19(0.34)$ & $7.51(0.02)$ & $10.01(0.01)$ & $2.08(0.35)$ & $5.20(0.07)$ & $0.02(0.99)$ & $1.93(0.38)$ & $9.65(0.01)$ \\
\hline Method & 1 & $33.48(<0.00)$ & $19.33(<0.00)$ & $1.50(0.22)$ & $13.43(<0.00)$ & $0.05(0.82)$ & $0.00(1.00)$ & $10.49(<0.00)$ & $6.92(0.01)$ \\
\hline Month & 3 & $4.14(0.25)$ & $3.74(0.29)$ & $1.12(0.77)$ & $4.77(0.19)$ & $1.96(0.58)$ & $0.00(1.00)$ & $3.10(0.38)$ & $4.61(0.20)$ \\
\hline Village/Year & 4 & $27.72(<0.00)$ & $5.45(0.24)$ & $21.73(<0.00)$ & $10.43(0.03)$ & $12.26(0.02)$ & $10.86(0.03)$ & $6.11(0.19)$ & $27.61(<0.00)$ \\
\hline Year/Method & 2 & $134.87(<0.00)$ & $32.29(<0.00)$ & $27.01(<0.00)$ & $31.02(<0.00)$ & $25.27(<0.00)$ & $0.32(0.85)$ & $6.86(0.03)$ & $110.90(<0.00)$ \\
\hline Year/Month & 6 & $1.17(0.98)$ & $11.33(0.08)$ & $4.61(0.59)$ & $6.83(0.34)$ & $8.26(0.22)$ & $8.88(0.18)$ & $7.09(0.31)$ & $2.53(0.87)$ \\
\hline Method/Month & 3 & $29.42(<0.00)$ & $14.71(<0.00)$ & $6.55(0.09)$ & $2.60(0.46)$ & $5.14(0.16)$ & $0.00(1.00)$ & $2.92(0.40)$ & $11.29(0.01)$ \\
\hline
\end{tabular}


Figure 1. a) Location of the research site and study villages, southeast Cameroon; b)

Zonation of land use by the three study villages, as instigated by the APGS according to

571 Epanda et al. (2005).

572

573 Figure 2. Monthly changes in average CPHD (catch per hunter per day) for all hunted animal species in three Cameroonian villages (Duomo Pierre, Malen V, Mimpala) (median, interquartile range, and whiskers indicating 95\% confidence intervals).

577 Tweedie regression lines are also shown.

Figure 3. Monthly changes in average CPHD (catch per hunter per day, $\pm 95 \%$

Cameroonian villages (Duomo Pierre, Malen V, Mimpala) during March-June in 2003, 2009 and 2016.

Figure 4. Monthly changes in average MBMI $(\mathrm{kg}, \pm 95 \%$ confidence intervals $)$ according to hunting method (firearms, traps) in three Cameroonian villages (Duomo Pierre, Malen V, Mimpala) during March-June in 2003, 2009 and 2016.

Figure 5. Monthly changes in average MBMI $(\mathrm{kg})$ for all hunted animal species in three Cameroonian villages (Duomo Pierre, Malen V, Mimpala) during March-June in 
591 range, and whiskers indicating 95\% confidence intervals). Tweedie regression lines are

592 also shown. 
Fig. 1.
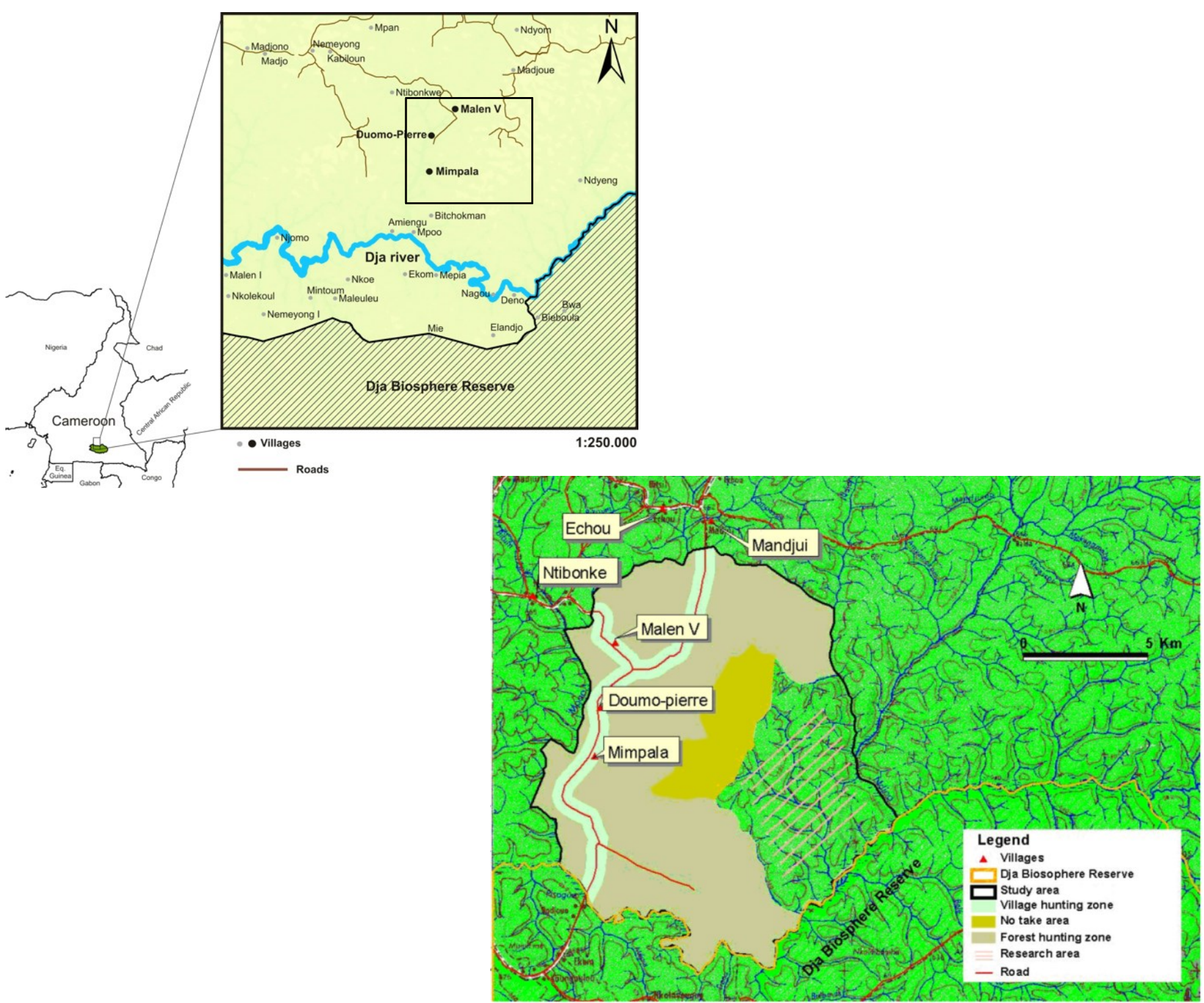
Fig. 2.

596

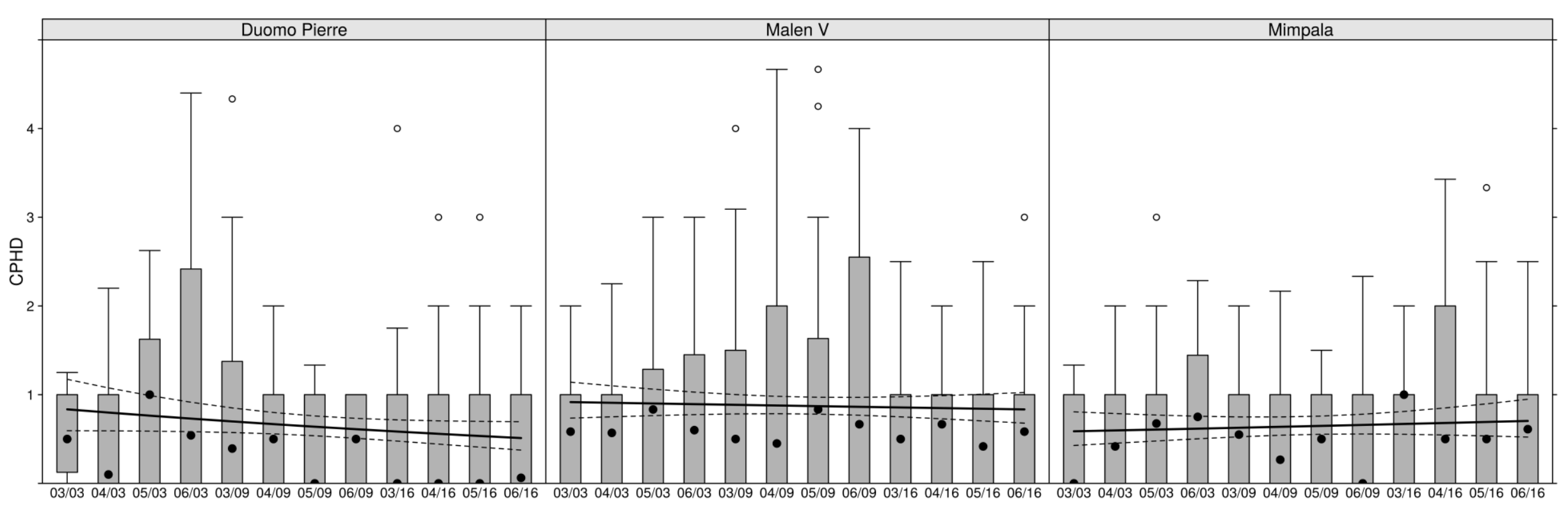


Fig. 3

599

600

601

602

603

604

605

606

607

608

609

610

611

612

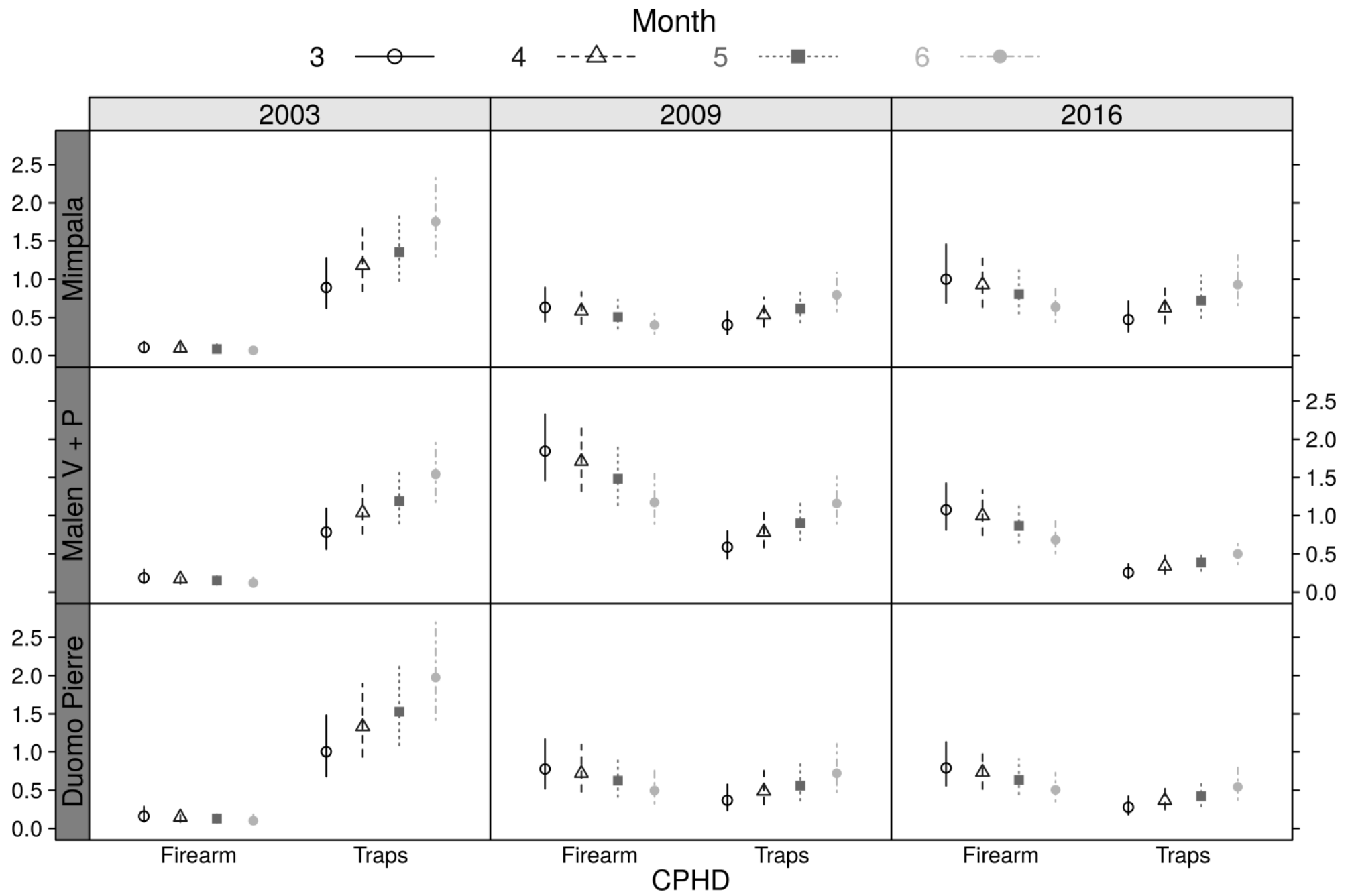


Fig. 4.

614

615

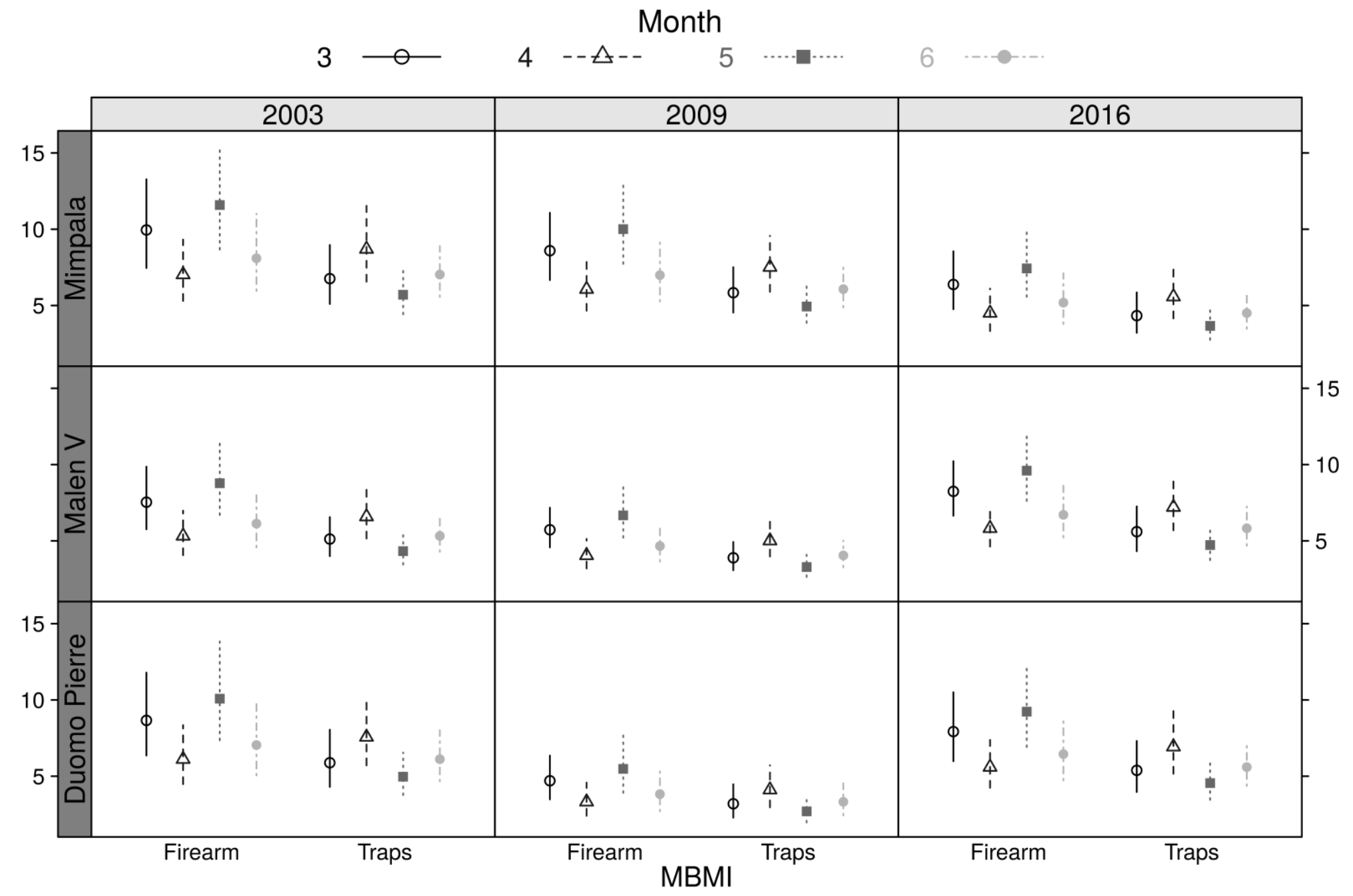

616 


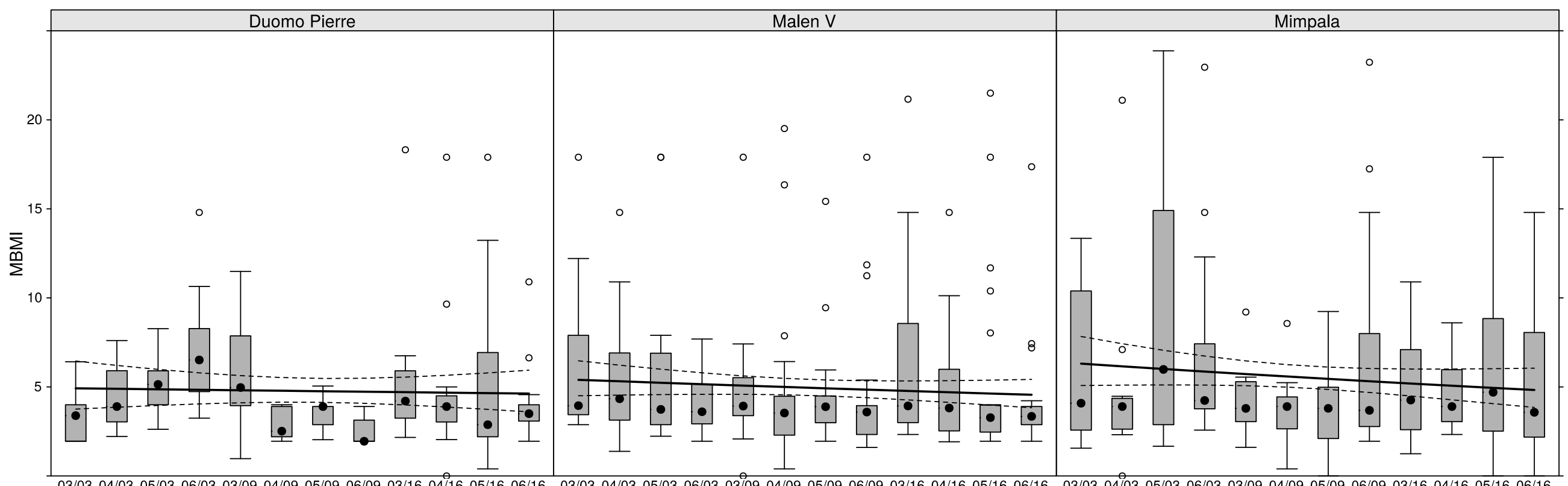

